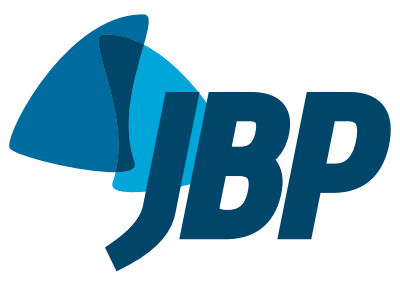

\title{
Identifying decreased diaphragmatic mobility and diaphragm thickening in interstitial lung disease: the utility of ultrasound imaging
}

\author{
Pauliane Vieira Santana ${ }^{1,2}$, Elena Prina ${ }^{1}$, André Luis Pereira Albuquerque ${ }^{1}$, \\ Carlos Roberto Ribeiro Carvalho', Pedro Caruso ${ }^{1,2}$
}

1. Divisão de Pneumologia, Instituto do Coração - InCor - Hospital das Clínicas, Faculdade de Medicina, Universidade de São Paulo, São Paulo (SP) Brasil.

2. A.C. Camargo Cancer Center, São Paulo (SP) Brasil.

Submitted: 21 October 2015

Accepted: 27 January 2016.

Financial support: This study received financial support from the Fundação de Amparo à Pesquisa do Estado de São Paulo (FAPESP, São Paulo Research Foundation; Grant no. 2010/08947-9). The funding body played no part in the design, implementation, or analysis of the study.

\begin{abstract}
Objective: To investigate the applicability of ultrasound imaging of the diaphragm in interstitial lung disease (ILD). Methods: Using ultrasound, we compared ILD patients and healthy volunteers (controls) in terms of diaphragmatic mobility during quiet and deep breathing; diaphragm thickness at functional residual capacity (FRC) and at total lung capacity (TLC); and the thickening fraction (TF, proportional diaphragm thickening from FRC to TLC). We also evaluated correlations between diaphragmatic dysfunction and lung function variables. Results: Between the ILD patients $(n=40)$ and the controls $(n=$ 16), mean diaphragmatic mobility was comparable during quiet breathing, although it was significantly lower in the patients during deep breathing $(4.5 \pm 1.7 \mathrm{~cm}$ vs. $7.6 \pm 1.4 \mathrm{~cm} ; \mathrm{p}<$ $0.01)$. The patients showed greater diaphragm thickness at FRC $(p=0.05)$, although, due to lower diaphragm thickness at TLC, they also showed a lower TF $(p<0.01)$. The FVC as a percentage of the predicted value (FVC\%) correlated with diaphragmatic mobility ( $r$ $=0.73 ; p<0.01)$, and an FVC $\%$ cut-off value of < $60 \%$ presented high sensitivity (92\%) and specificity (81\%) for indentifying decreased diaphragmatic mobility. Conclusions: Using ultrasound, we were able to show that diaphragmatic mobility and the TF were lower in ILD patients than in healthy controls, despite the greater diaphragm thickness at FRC in the former. Diaphragmatic mobility correlated with ILD functional severity, and an FVC\% cut-off value of $<60 \%$ was found to be highly accurate for indentifying diaphragmatic dysfunction on ultrasound.
\end{abstract}

Keywords: Diaphragm/ultrasonography; Lung diseases, interstitial; Respiratory muscles; Respiratory function tests.

\section{INTRODUCTION}

Interstitial lung diseases (ILDs) are a heterogeneous group of pulmonary disorders characterized by breathlessness and decreases in lung volume, gas exchange, and exercise tolerance, as well as by poorer quality of life and lower survival.(1) Although those characteristics have been attributed to the parenchymal involvement, that concept was recently challenged because it has also been found that peripheral muscle function is impaired in patients with ILD. ${ }^{(2-4)}$ In addition, diaphragm weakness and expiratory muscle fatigue after maximal exercise have been detected in ILD patients. ${ }^{(5-9)}$ The main hypotheses for respiratory muscle dysfunction in ILD are related to systemic inflammation, disuse, hypoxia, malnutrition, corticosteroid use, and overload due to the increased elastic recoil of the lung. $(6,7,10,11)$

Ultrasound imaging of the diaphragm has been broadly applied in some chronic respiratory diseases, such as COPD, asthma, cystic fibrosis, and diaphragmatic paralysis, as well as during weaning from mechanical ventilation. (12-19) In comparison with other imaging methods, this technique has diverse advantages, such as the absence of radiation, portability, real-time imaging, and the fact that it is noninvasive. In addition, reduced diaphragmatic mobility and diaphragm thickness, as determined by ultrasound, has proven to be a good predictor of failure to wean from mechanical ventilation ${ }^{(18)}$ and has been shown to correlate significantly with disease severity in COPD. ${ }^{(15)}$

We hypothesized that, on ultrasound, ILD patients would present diaphragm dysfunction, characterized by lower diaphragmatic mobility and less diaphragm thickening, when compared with healthy age- and gender-matched controls. We also hypothesized that such diaphragm dysfunction would correlate with the extent of the parenchymal involvement, as quantified by FVC, an index used in order to follow up and determine the prognosis in ILD patients. ${ }^{(20)}$

\section{METHODS}

\section{Patients and controls}

We recruited 40 consecutive patients from an ILD outpatient clinic at a tertiary care teaching hospital. The diagnosis of ILD was based on clinical features and pulmonary function test (PFT) results, as well as on the 
findings of CT scans of the chest, bronchoalveolar lavage, and (in some cases) lung biopsy. Patients were excluded if they required home oxygen therapy, had an active infection, or had been diagnosed with a neuromuscular disease associated with ILD. We recruited a control group of 16 healthy volunteers who were matched to the patients for age, gender, body mass index, and smoking status. The study was approved by the Research Ethics Committee of the University of São Paulo School of Medicine Hospital das Clínicas (Protocol no. 0835/11), and all participants gave written informed consent.

\section{Measurements}

We recorded demographic data, as well as data related to comorbidities, corticosteroid use, immunosuppression therapy, smoking, and dyspnea, as quantified with the modified Medical Research Council (mMRC) scale. ${ }^{(21)}$ Each of the patients and volunteers underwent PFTs and ultrasound imaging of the diaphragm on the same day.

\section{PFTs}

In all patients and control subjects, we used a calibrated pneumotachograph (Medical Graphics Corporation, St. Paul, MN, USA) to obtain the following variables: FVC, $\mathrm{FEV}_{1}$, and inspiratory capacity. Using a body plethysmograph (Elite Dx; Medical Graphics Corporation), we also measured lung volumes: functional residual capacity (FRC) and total lung capacity (TLC). Predicted values were those derived for the Brazilian population. ${ }^{(22)}$

\section{Ultrasound imaging of the diaphragm}

In all patients and controls, we performed ultrasound imaging of the diaphragm using a portable ultrasound system (Nanomaxx; Sonosite, Bothell, WA, USA). During the procedure, patients were in a semi-recumbent position with a peripheral oxygen saturation $\geq 92 \%$, receiving supplementary oxygen if necessary. For the evaluation of diaphragmatic mobility, we placed a 2-5 $\mathrm{MHz}$ convex transducer over the anterior subcostal region between the midclavicular and anterior axillary lines. The transducer was angled medially and anteriorly so that the ultrasound beam would reach the posterior third of the right hemidiaphragm. The ultrasound was used in B-mode to visualize the diaphragm and then in M-mode to measure the amplitude of the cranio-caudal diaphragmatic excursion during quiet breathing and deep breathing. ${ }^{(23,24)}$ We recorded the averaged value of three consecutive measurements. We also assessed the mobility of the diaphragm during a sniff test in order to exclude the presence of paradoxical movement.

Diaphragm thickness was measured in B-mode with a 6-13 $\mathrm{MHz}$ linear transducer placed over the diaphragm apposition zone, near the costophrenic angle, between the right anterior and medial axillary lines. Diaphragm thickness was measured from the most superficial hyperechoic line (pleural line) to the deepest hyperechoic line (peritoneal line).(25-27) We measured the thickness of the diaphragm at FRC and then at TLC. Again, the averaged value of three consecutive measurements was recorded for each. We also calculated the thickening fraction (TF, proportional thickening of the diaphragm from FRC to TLC), as defined by the following equation:

$\mathrm{TF}=[(\mathrm{Tmin}-\mathrm{Tmax}) / \mathrm{Tmin}] \times 100$

where Tmin is the minimum thickness of the diaphragm (measured at FRC) and Tmax is the maximum thickness of the diaphragm (measured at TLC).

\section{Statistical analysis}

Categorical data are presented as absolute and relative frequency. Continuous data are presented as mean \pm standard deviation or as median and $25-75 \%$ interquartile range, as appropriate. Categorical variables were compared using the chi-square test or Fisher's exact test. Continuous variables were compared using the Student's t-test or Mann-Whitney test, according to their distribution.

We used a linear model as well as an exponential model to correlate PFT variables with diaphragmatic mobility and diaphragm thickness. To identify the PFT variable that presented the strongest correlation with the diaphragmatic mobility or diaphragm thickness, we used a ROC curve, thus also identifying the best PFT cut-off value for identifying abnormalities in diaphragmatic mobility or diaphragm thickening. Diaphragmatic dysfunction was defined as showing values for diaphragmatic mobility or diaphragm thickness that were below the $95 \%$ confidence interval of the values obtained for the controls.

To adjust for possible confounders and to evaluate risk factors associated with the occurrence of diaphragmatic dysfunction, we performed a logistic regression analysis. To avoid overfitting of the logistic regression model, we did not use stepwise procedures and chose the predictor variables that yielded $p<0.20$ in a univariate regression analysis and had clinical relevance. Four independent variables (age, body mass index, the percentage of the predicted FVC, and the percentage of the predicted $\mathrm{FEV}_{1}$ ) were selected for the logistic regression model. Values of $p \leq 0.05$ were considered statistically significant. All statistical analyses were performed with the IBM SPSS Statistics software package, version 20.0 (IBM Corporation, Armonk, NY, USA).

\section{RESULTS}

The controls were well matched to the patients for age, gender, body mass index, and smoking status. As expected, lung volumes were lower in the ILD patients than in the controls (Table 1 ). The etiologies of the ILD were as follows: usual interstitial pneumonia ( $n=$ $6)$; nonspecific interstitial pneumonia $(n=7)$; fibrotic hypersensitivity pneumonitis ( $n=5)$; giant mixed desquamative interstitial pneumonia $(n=1)$; associated connective tissue disease $(n=9)$; sarcoidosis $(n=2)$; pneumoconiosis $(n=2)$; and unknown $(n=8)$. Most of the patients had never used corticosteroids. However, 
a significant proportion had breathlessness, more than $60 \%$ scoring $\geq 2$ on the mMRC scale (Table 1 ).

Diaphragmatic mobility during quiet breathing did not differ significantly between the patients and the controls. However, during deep breathing, the degree of diaphragmatic mobility was lower in the patients (Table 2). None of the patients presented paradoxical movement of the diaphragm during the sniff test.

The diaphragm thickness at FRC was significantly higher in the patients than in the controls. However, the diaphragm thickness at TLC was significantly lower in the patients, resulting in a lower TF (Table 2).

None of the PFT variables correlated with diaphragm thickness at FRC, diaphragm thickness at TLC, the
TF, or diaphragmatic mobility during quiet breathing (Table 3). However, diaphragmatic mobility during deep breathing correlated with all of the PFT variables (Table 3). The correlations were slightly stronger when we used exponential fitting than when we used linear fitting (Figure 1), and the strongest correlation was for FVC as a percentage of the predicted value; patients with lower FVC had lower diaphragmatic mobility during deep breathing. After we adjusted for confounders (age, body mass index, and the percentage of the predicted $\mathrm{FEV}_{1}$ ), the percentage of the predicted FVC was the only factor associated with decreased diaphragmatic mobility during deep breathing $(p=0.01)$, as shown in Table 4.

Table 1. Characteristics of healthy volunteers (controls) and interstitial lung disease patients. ${ }^{\text {a }}$

\begin{tabular}{|c|c|c|c|}
\hline \multirow[t]{2}{*}{ Characteristic } & Controls & Patients & \multirow[t]{2}{*}{$\mathbf{p}$} \\
\hline & $(n=16)$ & $(n=40)$ & \\
\hline Age, years & $55 \pm 11$ & $55 \pm 15$ & 0.81 \\
\hline Male gender, n (\%) & $8(50)$ & $23(57)$ & 0.61 \\
\hline $\mathrm{BMI}, \mathrm{kg} / \mathrm{m}^{2}$ & $26.8 \pm 3.6$ & $25.6 \pm 4.5$ & 0.32 \\
\hline Smoking status, n (\%) & & & 0.99 \\
\hline Never smoker & $12(75)$ & $30(75)$ & \\
\hline Former smoker & $4(25)$ & $10(25)$ & \\
\hline Current smoker & 0 & 0 & \\
\hline FVC, L & $3.26 \pm 0.73$ & $1.96 \pm 0.71$ & $<0.01$ \\
\hline FVC, $\%$ of predicted & $88 \pm 9$ & $57 \pm 16$ & $<0.01$ \\
\hline $\mathrm{FEV}_{1}, \mathrm{~L}$ & $2.68 \pm 0.63$ & $1.67 \pm 0.58$ & $<0.01$ \\
\hline $\mathrm{FEV}_{1}, \%$ of predicted & $90 \pm 10$ & $62 \pm 19$ & $<0.01$ \\
\hline $\mathrm{FEV}_{1} / \mathrm{FVC}$ ratio & $0.82 \pm 0.05$ & $0.85 \pm 0.06$ & 0.04 \\
\hline TLC, $\%$ of predicted & & $61 \pm 12$ & \\
\hline \multicolumn{4}{|l|}{ Corticosteroid use, n (\%) } \\
\hline Never & - & $24(60)$ & \\
\hline Current & - & $16(40)$ & \\
\hline Prednisone, $<20 \mathrm{mg} /$ day & - & $10(62.5)$ & \\
\hline Prednisone, $\geq 20 \mathrm{mg} /$ day & - & $6(37.5)$ & \\
\hline \multicolumn{4}{|l|}{ mMRC scale score, $\mathrm{n}(\%)$} \\
\hline 0 (no dyspnea) & - & $0(0)$ & \\
\hline 1 (mild dyspnea) & - & $12(30)$ & \\
\hline 2 (moderate dyspnea) & - & $16(40)$ & \\
\hline 3 (severe dyspnea) & - & $10(25)$ & \\
\hline 4 (very severe dyspnea) & - & $2(5)$ & \\
\hline
\end{tabular}

avalues expressed as mean $\pm S D$, except where otherwise indicated. BMI: body mass index; TLC: total lung capacity; and mMRC: modified Medical Research Council.

Table 2. Diaphragmatic mobility, diaphragm thickness, and the thickening fraction (proportional diaphragm thickening from functional residual capacity to total lung capacity) in interstitial lung disease patients and healthy volunteers (controls).

\begin{tabular}{lccc}
\multicolumn{1}{c}{ Variable } & $\begin{array}{c}\text { Controls } \\
(\mathbf{n}=\mathbf{1 6})\end{array}$ & $\begin{array}{c}\text { Patients } \\
(\mathbf{n}=\mathbf{4 0})\end{array}$ & $\mathbf{p}$ \\
\hline $\begin{array}{l}\text { Diaphragmatic mobility } \\
\quad \text { During quiet breathing }(\mathrm{cm})\end{array}$ & $1.78 \pm 0.58$ & $1.80 \pm 0.67$ & 0.91 \\
$\quad \begin{array}{l}\text { During deep breathing }(\mathrm{cm}) \\
\text { Diaphragm thickness }\end{array}$ & $7.62 \pm 1.44$ & $4.46 \pm 1.73$ & 0.01 \\
$\quad \begin{array}{l}\text { At functional residual } \\
\text { capacity (cm) }\end{array}$ & $0.17 \pm 0.04$ & $0.19 \pm 0.03$ & 0.05 \\
$\quad$ At total lung capacity $(\mathrm{cm})$ & $0.40 \pm 0.10$ & $0.32 \pm 0.08$ & $<0.01$ \\
Thickening fraction $(\%)$ & $131 \pm 55$ & $62 \pm 32$ & $<0.01$ \\
\hline
\end{tabular}

avalues expressed as mean \pm SD. 
The $95 \%$ confidence interval for diaphragmatic mobility during deep breathing was $4.80-10.44 \mathrm{~cm}$, and values below $4.80 \mathrm{~cm}$ during deep breathing were therefore considered indicative of decreased diaphragmatic mobility. A cut-off value of $60 \%$ of the predicted FVC had the highest accuracy for identifying decreased diaphragmatic mobility, with a sensitivity of $92 \%$, a specificity of $81 \%$, a positive predictive value of $88 \%$, and a negative predictive value of $87 \%$ (Figure 2 ).

\section{DISCUSSION}

In the present study, we showed that patients with ILD presented decreased diaphragmatic mobility during deep breathing and a lower TF, in comparison with the control subjects. We also showed that diaphragmatic dysfunction is associated with the percentage of the predicted FVC and that a cut-off value of $60 \%$ of the predicted FVC has high accuracy for the diagnosis of diaphragm dysfunction.

The standardization of techniques has made the measurement of diaphragmatic mobility and diaphragm thickness feasible and reproducible, promoting the use of ultrasound imaging of the diaphragm in many respiratory diseases, such as asthma, cystic fibrosis, COPD, diaphragmatic paralysis, acute respiratory failure, and mechanical ventilation weaning. ${ }^{(12-14,17,28)}$ To our knowledge, there has been only one previous study using ultrasound to evaluate the diaphragms of ILD patients and showing that diaphragmatic mobility was similar between ILD patients and healthy controls. ${ }^{(23)}$ However, the sample in that study was small (18 patients) and was composed exclusively of patients with idiopathic pulmonary fibrosis. In addition, the authors did not evaluate diaphragm thickness. ${ }^{(29)}$

There are several possible causes of diaphragm atrophy in ILD patients, such causes including systemic inflammation, disuse, hypoxia, malnutrition, and respiratory myopathy secondary to the use of corticosteroids. ${ }^{(6,7,10,11)}$ In contrast, the diaphragm overload resulting from the increased elastic recoil of the lung can, due to a training effect, increase diaphragm muscle mass. ${ }^{(30)}$ The effects of those opposing forces depend on the extent of the parenchymal involvement, disease duration, use of drugs, hypoxemia level, physical activity level, and individual susceptibility. Previous studies using volitional tests reported unaltered respiratory muscle function in ILD patients. ${ }^{(31,32)}$ However, two recent studies using non-volitional tests, although not employing ultrasound, demonstrated respiratory muscle dysfunction in ILD patients. ${ }^{(5,9)}$ These discrepant results regarding the impact of the ILD on inspiratory muscle strength might be due to differences in the severity of ILD among the studies.

In patients with COPD, it has been shown that lung hyperinflation shifts the diaphragm caudally, imposing a mechanical disadvantage upon it. ${ }^{(33)}$ In contrast, the decreased lung volume in ILD patients dislodges the diaphragm cranially, imposing an equivalent mechanical disadvantage, although it does so by shortening the radius of the diaphragm. In addition, the increased elastic recoil of the lung impairs diaphragmatic mobility during inspiration. Therefore, it should not

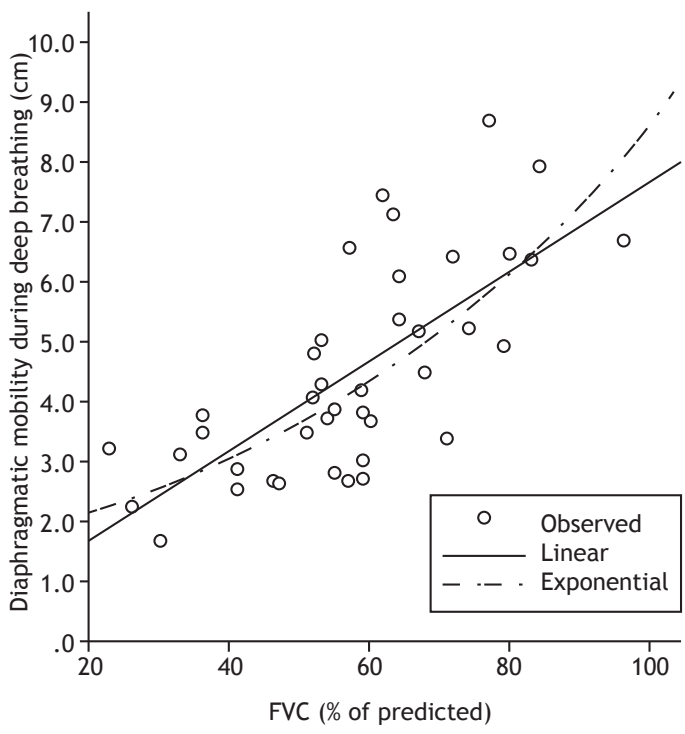

Figure 1. Linear and exponential correlations between diaphragmatic mobility during deep breathing and FVC as a percentage of the predicted value.

Table 3. Pulmonary function test variables in correlation with diaphragmatic mobility during deep breathing and with the thickening fraction (proportional diaphragm thickening from functional residual capacity to total lung capacity).

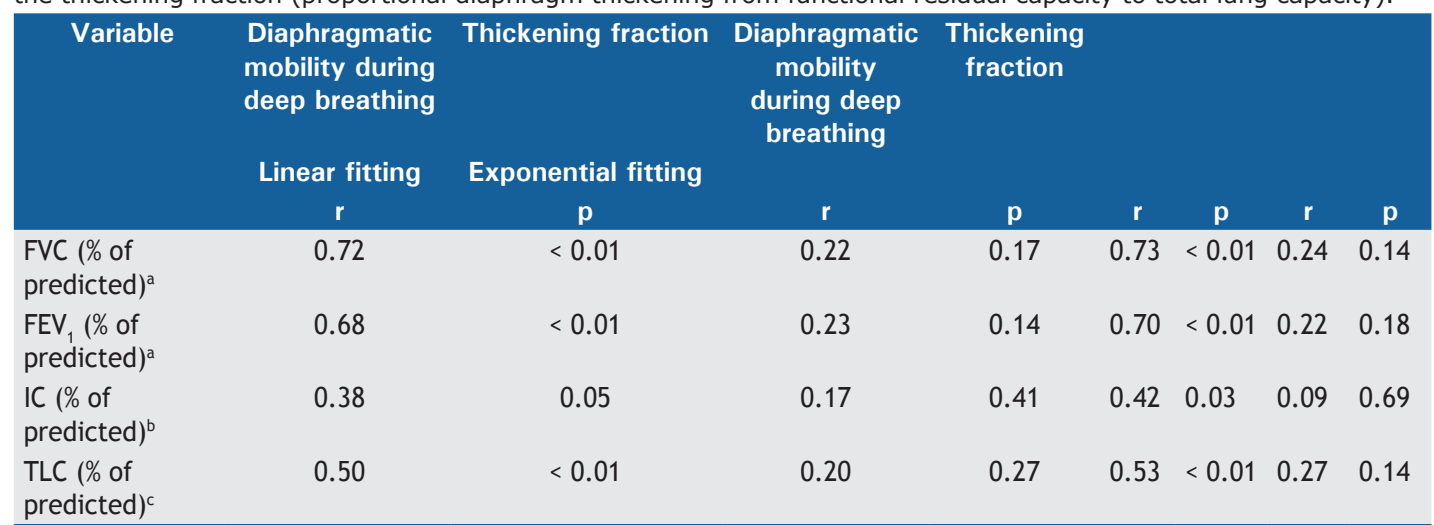

IC: inspiratory capacity; and TLC: total lung capacity. ${ }^{a} n=40 .{ }^{b} n=25 .{ }^{c} n=31$. 
Table 4. Comparison between interstitial lung disease patients with and without diaphragmatic dysfunction.

\begin{tabular}{|c|c|c|c|c|c|}
\hline Variable & $\begin{array}{c}\text { Diaphragmatic } \\
\text { dysfunction } \\
\text { No } \\
(n=16)\end{array}$ & $\begin{array}{c}\text { p } \\
\text { Yes } \\
(n=24)\end{array}$ & $\begin{array}{c}\text { Diaphragmatic } \\
\text { dysfunction }\end{array}$ & OR (95\% CI) & \\
\hline Age, years & $61 \pm 10$ & $52 \pm 17$ & 0.04 & $-0.003(-0.01$ to 0.006$)$ & 0.82 \\
\hline Male gender, n (\%) & $11(48)$ & $12(52)$ & 0.32 & & \\
\hline Body mass index, $\mathrm{kg} / \mathrm{m}^{2}$ & $27.4 \pm 3.4$ & $24.5 \pm 4.9$ & 0.04 & $-0.01(-0.04$ to 0.01$)$ & 0.30 \\
\hline FVC, $\%$ of predicted & $70 \pm 12$ & $49 \pm 13$ & $<0.01$ & $-0.03(-0.06$ to -0.01$)$ & 0.04 \\
\hline $\mathrm{FEV}_{1}, \%$ of predicted & $76 \pm 14$ & $53 \pm 16$ & $<0.01$ & $0.12(-0.01$ to 0.37$)$ & 0.34 \\
\hline Corticosteroid use, $\mathrm{n}(\%)$ & $6(37)$ & $11(46)$ & 0.75 & & \\
\hline
\end{tabular}

alues expressed as mean $\pm S D$, except where otherwise indicated.

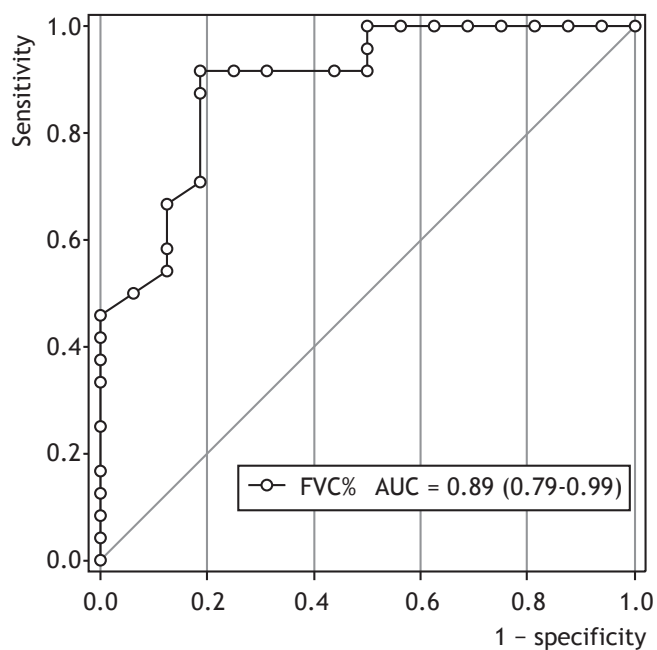

Figure 2. ROC curve of FVC as a percentage of the predicted value (FVC\%) and the occurrence of decreased diaphragmatic mobility, showing the area under the curve (AUC).

be surprising that diaphragmatic mobility is reduced under these conditions of reduced lung volumes. However, the relationship between pulmonary volume and diaphragm excursion is debated and controversial in the literature. Cohen et al., (34) studying ten normal subjects, recorded simultaneously the diaphragmatic excursion (using ultrasound in M-mode) and the tidal volume at different inspiratory volumes. The authors found that, at $15-87 \%$ of inspiratory capacity, there was a linear relationship between diaphragmatic excursion and tidal volume. (34) Houston et al., (35) assessing hemidiaphragmatic movement, also found a linear relationship between inspiratory lung volume and diaphragmatic excursion. Another study, designed to validate ultrasound imaging of the diaphragm as an alternative to whole-body plethysmography, showed that the mean diaphragmatic excursion (during quiet breathing and at maximal sniff) correlated poorly with all of the lung volumes measured, although the authors did not investigate excursion during deep breathing. (36) Fedullo et al., (37) investigating diaphragmatic motion after coronary artery bypass surgery, found no relationship between diaphragmatic mobility and vital capacity.

Similar to other studies that evaluated diaphragm thickness using ultrasound in other respiratory diseases, the present study showed that ILD patients presented a thicker diaphragm at FRC than did healthy controls, supporting the hypothesis of diaphragm thickening in response to respiratory muscle overload. ${ }^{(13,16)}$ However, the greater diaphragm thickness at FRC resulted in a lower TF, probably indicating dysfunctional muscular hypertrophy or "pseudohypertrophy", as has previously been demonstrated in the diaphragms of young patients with Duchenne muscular dystrophy. ${ }^{(38)}$ In ILD, the diaphragm appears to thicken over time but is unable to increase during maximal inspiration, unlike the physiological pattern seen in healthy controls.

The results of the present study demonstrate that ultrasound imaging of the diaphragm is a feasible method to evaluate diaphragmatic function. Diaphragmatic mobility is correlated with lung volume, a correlation that has been described in other lung diseases, such as COPD. ${ }^{(39)}$ In clinical practice, ultrasound imaging of the diaphragm has high sensitivity and specificity to identify reduced diaphragmatic mobility in ILD patients with an FVC $<60 \%$ of the predicted value.

We showed that ultrasound imaging of the diaphragm is associated with PFT variables and that PFT trends constitute a major prognostic determinant of ILD. Therefore, we believe that ultrasound can be added to the arsenal of methods to follow up patients with ILD. ${ }^{(20)}$ In addition to the chronic course of ILD, the identification of diaphragm dysfunction could alert physicians to the need to avoid or change the use of drugs that induce myopathy, such as corticosteroids.

The main limitation of our study was that we did not measure diaphragm force. However, Ueki et al. (27) found that a higher thickening ratio was strongly correlated with inspiratory strength in healthy subjects. Another study also showed a strong correlation between maximal inspiratory pressure and the TF in patients recovering from diaphragmatic paralysis. ${ }^{(40)}$ In addition, because our results show not only reduced diaphragmatic mobility but also a reduced TF, we can conclude that diaphragmatic dysfunction is common in ILD patients. Another limitation is that, although our study has a power of $100 \%$ to estimate the coefficient of correlation between PFT and diaphragmatic mobility, it has a power of only approximately $40 \%$ to estimate that between PFT and diaphragm thickening.

In comparison with healthy controls, patients with ILD show reduced diaphragmatic mobility and a lower TF. 
In addition, the cut-off point of an FVC $<60 \%$ of the predicted value showed high accuracy and sensitivity to identify decreased diaphragmatic mobility, as well being significantly associated with impaired lung function. The use of the results of ultrasound imaging of the diaphragm as a follow-up parameter and its relationship to respiratory muscle strength remain to be investigated.

\section{REFERENCES}

1. American Thoracic S, European Respiratory S. American Thoracic Society/European Respiratory Society International Multidisciplinary Consensus Classification of the Idiopathic Interstitial Pneumonias. This joint statement of the American Thoracic Society (ATS), and the European Respiratory Society (ERS) was adopted by the ATS board of directors, June 2001 and by the ERS Executive Committee, June 2001. Am J Respir Crit Care Med. 2002;165(2):277-304. Erratum in: Am J Respir Crit Care Med. 2002;166(3):426. http://dx.doi. org/10.1164/ajrccm.165.2.ats01

2. Mendoza L, Gogali A, Shrikrishna D, Cavada G, Kemp SV, Natanek $\mathrm{SA}$, et al. Quadriceps strength and endurance in fibrotic idiopathic interstitial pneumonia. Respirology. 2014;19(1):138-43. http://dx.doi. org/10.1111/resp.12181

3. Spruit MA, Thomeer MJ, Gosselink R, Troosters T, Kasran A, Debrock AJ, et al. Skeletal muscle weakness in patients with sarcoidosis and its relationship with exercise intolerance and reduced health status. Thorax. 2005;60(1):32-8. http://dx.doi.org/10.1136/thx.2004.022244

4. Watanabe F, Taniguchi H, Sakamoto K, Kondoh Y, Kimura T, Kataoka K, et al. Quadriceps weakness contributes to exercise capacity in nonspecific interstitial pneumonia. Respir Med. 2013;107(4):622-8. http://dx.doi.org/10.1016/j.rmed.2012.12.013

5. Elia D, Kelly JL, Martolini D, Renzoni EA, Boutou AK, Chetta A, et al. Respiratory muscle fatigue following exercise in patients with interstitial lung disease. Respiration. 2013;85(3):220-7. http://dx.doi. org/10.1159/000338787

6. Hansen JE, Wasserman K. Pathophysiology of activity limitation in patients with interstitial lung disease. Chest. 1996;109(6):1566-76. http://dx.doi.org/10.1378/chest.109.6.1566

7. Holland AE. Exercise limitation in interstitial lung disease mechanisms, significance and therapeutic options. Chron Respir Dis 2010;7(2):101-11. http://dx.doi.org/10.1177/1479972309354689

8. O'Donnell DE, Chau LK, Webb KA. Qualitative aspects of exertional dyspnea in patients with interstitial lung disease. J Appl Physiol (1985). 1998;84(6):2000-9

9. Walterspacher S, Schlager D, Walker DJ, Müller-Quernheim J, Windisch W, Kabitz HJ. Respiratory muscle function in interstitial lung disease. Eur Respir J. 2013;42(1):211-9. http://dx.doi. org/10.1183/09031936.00109512

10. Dekhuijzen PN, Decramer M. Steroid-induced myopathy and its significance to respiratory disease: a known disease rediscovered. Eur Respir J. 1992;5(8):997-1003.

11. Prasse A, Müller-Quernheim J. Non-invasive biomarkers in pulmonary fibrosis. Respirology. 2009;14(6):788-95. http://dx.doi. org/10.1111/j.1440-1843.2009.01600.x

12. Baria MR, Shahgholi L, Sorenson EJ, Harper CJ, Lim KG, Strommen JA, et al. B-mode ultrasound assessment of diaphragm structure and function in patients with COPD. Chest. 2014;146(3):680-5. http:// dx.doi.org/10.1378/chest.13-2306

13. de Bruin PF, Ueki J, Watson A, Pride NB. Size and strength of the respiratory and quadriceps muscles in patients with chronic asthma. Eur Respir J. 1997;10(1):59-64. http://dx.doi.org/10.1183/09031936. 97.10010059

14. DiNino E, Gartman EJ, Sethi JM, McCool FD. Diaphragm ultrasound as a predictor of successful extubation from mechanical ventilation. Thorax. 2014;69(5):423-7. http://dx.doi.org/10.1136/ thoraxjnl-2013-204111

15. Dos Santos Yamaguti WP, Paulin E, Shibao S, Chammas MC, Salge JM, Ribeiro M, et al. Air trapping: The major factor limiting diaphragm mobility in chronic obstructive pulmonary disease patients. Respirology. 2008;13(1):138-44. http://dx.doi.org/10.1111/j.14401843.2007.01194.x

16. Dufresne V, Knoop C, Van Muylem A, Malfroot A, Lamotte $M$, Opdekamp C, et al. Effect of systemic inflammation on inspiratory and limb muscle strength and bulk in cystic fibrosis. Am J Respir Crit Care Med. 2009;180(2):153-8. http://dx.doi.org/10.1164/ rccm.200802-2320C

17. Gottesman E, McCool FD. Ultrasound evaluation of the paralyzed diaphragm. Am J Respir Crit Care Med. 1997;155(5):1570-4. http:// dx.doi.org/10.1164/ajrccm.155.5.9154859

18. Kim WY, Suh HJ, Hong SB, Koh Y, Lim CM. Diaphragm dysfunction assessed by ultrasonography: influence on weaning from mechanical ventilation. Crit Care Med. 2011;39(12):2627-30. http://dx.doi. org/10.1097/ccm.0b013e3182266408

19. Caruso P, Albuquerque AL, Santana PV, Cardenas LZ, Ferreira JG Prina $E$, et al. Diagnostic methods to assess inspiratory and expiratory muscle strength. J Bras Pneumol. 2015;41(2):110-23. http://dx.doi. org/10.1590/S1806-37132015000004474

20. Latsi PI, du Bois RM, Nicholson AG, Colby TV, Bisirtzoglou D, Nikolakopoulou $A$, et al. Fibrotic idiopathic interstitial pneumonia: the prognostic value of longitudinal functional trends. Am J Respir Crit Care Med. 2003;168(5):531-7. http://dx.doi.org/10.1164/ rccm.200210-12450C

21. Mahler DA, Weinberg DH, Wells CK, Feinstein AR. The measurement of dyspnea. Contents, interobserver agreement, and physiologic correlates of two new clinical indexes. Chest. 1984;85(6):751-8. http://dx.doi.org/10.1378/chest.85.6.751

22. Pereira CA, Sato T, Rodrigues SC. New reference values for forced spirometry in white adults in Brazil. J Bras Pneumol. 2007;33(4):397406. http://dx.doi.org/10.1590/S1806-37132007000400008

23. Boussuges A, Gole Y, Blanc P. Diaphragmatic motion studied by m-mode ultrasonography: methods, reproducibility, and normal values. Chest. 2009;135(2):391-400. http://dx.doi.org/10.1378/ chest.08-1541

24. Testa A, Soldati G, Giannuzzi R, Berardi S, Portale G, Gentilon Silveri N. Ultrasound M-mode assessment of diaphragmatic kinetics by anterior transverse scanning in healthy subjects. Ultrasound Med Biol. 2011;37(1):44-52. http://dx.doi.org/10.1016/j. ultrasmedbio.2010.10.004

25. Boon AJ, Harper CJ, Ghahfarokhi LS, Strommen JA, Watson JC, Sorenson EJ. Two-dimensional ultrasound imaging of the diaphragm: quantitative values in normal subjects. Muscle Nerve. 2013;47(6):884-9. http://dx.doi.org/10.1002/mus.23702

26. Cohn D, Benditt JO, Eveloff S, McCool FD. Diaphragm thickening during inspiration. J Appl Physiol (1985). 1997;83(1):291-6.

27. Ueki J, De Bruin PF, Pride NB. In vivo assessment of diaphragm contraction by ultrasound in normal subjects. Thorax. 1995;50(11):1157-61. http://dx.doi.org/10.1136/thx.50.11.1157

28. Pinet $C$, Cassart M, Scillia P, Lamotte M, Knoop C, Casimir G, et al. Function and bulk of respiratory and limb muscles in patients with cystic fibrosis. Am J Respir Crit Care Med. 2003;168(8):989-94. http://dx.doi.org/10.1164/rccm.200303-3980C

29. He L, Zhang W, Zhang J, Cao L, Gong L, Ma J, et al. Diaphragmatic motion studied by M-mode ultrasonography in combined pulmonary fibrosis and emphysema. Lung. 2014;192(4):553-61. http://dx.doi. org/10.1007/s00408-014-9594-5

30. de Troyer A, Yernault JC. Inspiratory muscle force in normal subjects and patients with interstitial lung disease. Thorax. 1980;35(2):92-100. http://dx.doi.org/10.1136/thx.35.2.92

31. Garcia-Rio F, Pino JM, Ruiz A, Diaz S, Prados C, Villamor J. Accuracy of noninvasive estimates of respiratory muscle effort during spontaneous breathing in restrictive diseases. J App Physiol (1985). 2003;95(4):1542-9. http://dx.doi.org/10.1152/ japplphysiol.01010.2002

32. Nishimura $Y$, Hida $W$, Taguchi $O$, Sakurai $M$, Ichinose $M$, Inoue $H$, et al. Respiratory muscle strength and gas exchange in neuromuscular diseases: comparison with chronic pulmonary emphysema and idiopathic pulmonary fibrosis. Tohoku J Exp Med. 1989:159(1):57-68. http://dx.doi.org/10.1620/tjem.159.57

33. De Troyer A. Effect of hyperinflation on the diaphragm. Eur Respir J. 1997;10(3):708-13

34. Cohen E, Mier A, Heywood P, Murphy K, Boultbee J, Guz A Excursion-volume relation of the right hemidiaphragm measured by ultrasonography and respiratory airflow measurements. Thorax. 1994;49(9):885-9. http://dx.doi.org/10.1136/thx.49.9.885 
Identifying decreased diaphragmatic mobility and diaphragm thickening in

interstitial lung disease: the utility of ultrasound imaging

35. Houston JG, Angus RM, Cowan MD, McMillan NC, Thomson NC Ultrasound assessment of normal hemidiaphragmatic movement: relation to inspiratory volume. Thorax. 1994;49(5):500-3. http://dx.doi. org/10.1136/thx.49.5.500

36. Scott S, Fuld JP, Carter R, McEntegart M, MacFarlane NG. Diaphragm ultrasonography as an alternative to whole-body plethysmography in pulmonary function testing. J Ultrasound Med. 2006;25(2):225-32.

37. Fedullo AJ, Lerner RM, Gibson J, Shayne DS. Sonographic measurement of diaphragmatic motion after coronary artery bypass surgery. Chest. 1992;102(6):1683-6. http://dx.doi.org/10.1378/ chest.102.6.1683
38. De Bruin PF, Ueki J, Bush A, Khan Y, Watson A, Pride NB. Diaphragm thickness and inspiratory strength in patients with Duchenne muscular dystrophy. Thorax. 1997;52(5):472-5. http://dx.doi. org/10.1136/thx.52.5.472

39. Levine $S$, Nguyen T, Kaiser LR, Rubinstein NA, Maislin G, Gregory $C$, et al. Human diaphragm remodeling associated with chronic obstructive pulmonary disease: clinical implications. Am J Respir Crit Care Med. 2003;168(6):706-13. http://dx.doi.org/10.1164/ rccm.200209-10700C

40. Summerhill EM, El-Sameed YA, Glidden TJ, McCool FD. Monitoring recovery from diaphragm paralysis with ultrasound. Chest. 2008;133(3):737-43. http://dx.doi.org/10.1378/chest.07-2200 